\title{
DNA Oxidation in Patients with Metastastic Colorectal Cancer: Clinical Significance of 8-Hydroxy-Deoxyguanosine as an Independent Prognostic Factor
}

\author{
Anatoliy Burlaka ${ }^{1}$, Anastasia Vovk $^{1}$, Anton Burlaka ${ }^{2}$, Olena Kolesnik ${ }^{2}$
}

Corresponding author:

Anton Burlaka, MD, PhD

National Cancer Institute, Kyiv, Ukraine

E-mail: nir.burlaka@gmail.com
${ }^{1}$ R.E. Kavetsly Institute of Experimental Pathology, Oncology and Radiobiology, National Academy of Sciences of Ukraine, Kyiv, Ukraine

${ }^{2}$ National Cancer Institute, Ministry of Health of Ukraine, Kyiv, Ukraine

\section{ABSTRACT}

Introduction: Prognosis of metastatic colorectal cancer (mCRC) patients nowadays is an important subject in the field of oncology. R0-resection of colon with primary tumor and liver metastasis remains the only treatment which significantly improves survival rate. However, recent experimental data shows that surgical trauma can indirectly stimulate tumor growth due to mitochondrial dysfunction and unregulated superoxide radical (02-.) generation.

Aim: To study the clinical significance of 8-hydroxy-deoxyguanosine (8-OHdGu) marker, to assess the oncological effects of heat ischemia of liver parenchyma on disease prognosis in patients with $\mathrm{MCRC}$.

Material and methods: 69 urine 24-hour volume tests of patients with $\mathrm{mCRC}$ and 17 healthy individuals studied. Urine 8-OHdGu level measured using spectrophotometric method with pre-solid phase DNA extraction. The energy system and hepatocyte detoxification system state,levels of 02-. in tumor tissue determined using method of electron paramagnetic resonance (EPR) and SpinTraps technology at room temperature. Experiments carried out on a computerized EPR spectrometer RE-1307. EPR spectra recorded at temperature of liquid nitrogen $\left(-196^{\circ} \mathrm{C}\right)$ in paramagnetically pure quartz dewar on a computerized spectrometer PE-1307 with resonator H011. Error of the method of spectrum integration and spread of spectrum reproduction of one sample is not more than $3 \%$.

Results: The average level of marker in healthy individuals was $0.244 \pm 0.063 \mathrm{nM} / \mathrm{kg}$ · day, whereas before the resection and on day 3 after the R0-resection of liver in mCRC patients $-3.42 \pm 0.18 \mathrm{nM} / \mathrm{kg} \cdot$ day and $2,12 \pm 0,08 \mathrm{nM} / \mathrm{kg} \cdot$ days $(\mathrm{p}<0,05)$, respectively. On day 3 after the liver resection due to its metastatic lesions with a total duration of heat ischemia period $<30 \mathrm{~min}$ and $>30 \mathrm{~min}$ have had marker at level 2,108 $\pm 0.13 \mathrm{nM} / \mathrm{kg} \cdot$ day and $2.9883 \pm 0.159 \mathrm{nM} / \mathrm{kg} \cdot$ day $(\mathrm{p}<0.0001)$, respectively. The volume of metastatic tissue significantly and directly corelated with the level of urine $8-\operatorname{oxodGu}\left(R^{2}=0.54,95 \% \mathrm{Cl}\right.$ : $0.037-0.0991, p<0.000$ ) ,also duration of surgical intervention( $\geq 300 \mathrm{~min}$ ) and duration of worm liver ischemia( $>30$ min.) during the surgery significantly increased urine level of 8-oxodGu (R2 = 0.54, 95\% Cl: $0.001-0.004, p<0.001)$.

Conclusions: Worm liver ischemia ( $>30 \mathrm{~min}$.), long-term surgical intervention ( $\geq 300 \mathrm{~min}$ ) and metastatic tissue volume $\left(\geq 12 \mathrm{~cm}^{3}\right)$ in liver parenchyma in $\mathrm{mCRC}$ patients significantly increase urine $8-0 \mathrm{HdGu}$ levels. R0-resection of liver metastases in mCRC patients dicreases urine $8-0 \mathrm{HdGu}$ levels already on day 3 after the surgery. 8-0HdGu is a new factor of oncological prognosis in patients with $\mathrm{mCRC}$.

Key words: colorectal cancer, liver metastases, resection, warm ischemia injury, DNA damage 


\section{INTRODUCTION}

In more than $30 \%$ of patients with colorectal cancer with metastatic lesion of liver ( $\mathrm{mCRC}$ ), during the first year after the liver resection repeated metastatic lesions diagnosed, and its recurrent metastatic lesion occurs since the time of first resection (1) in $50-60 \%$ patients. Local and systemic control of the disease course in $\mathrm{MCRC}$ patients is akey point of modern oncology; and individualized prediction of the disease course in $\mathrm{mCRC}$ patients is the subject of active research. Recently, prognosis of such patients depended predominantly on clinical, radiological, pathological, and molecular criteria, but this approach did not demonstrate sufficient clinical efficacy (2).

Ischemia-reperfusion ( $(/ \mathrm{P})$ effect in liver usually recorded in case of large as well as advanced liver resections using Pringle maneuver (PM) and/or total blood supply blockage in organ (3). It's proven that liver oxygenation is significantly reduced during the organ mobilization/retraction and its preparation for the latter transection of parenchyma, which leads to additional hepatocytes damage and death (4). Liver with signs of fibrosis, steatosis due to toxic effect of chemotherapy (HT) is much more susceptible to damage caused by I/P (5). On animal models shown that damage due to MP and $\mathrm{I} / \mathrm{P}$ during the liver resection leads to hepatocytes dysfunction, an increase of anti-inflammatory cytokines levels, enhanced activity of metastatic metalloproteinases, which in turn may stimulate the progression of micrometastases of mCRC carcinoma (6). Surgical trauma creates favorable conditions for the growth of uncontrolled concentrations of superoxide radicals (O2-.) which in turn creates a new redox state in surgerytreated organ and organism in general, which is a key factor in local relapse and distant metastases after the tumor resection performed (7).

Recently, number of centers focused on current problem studying substantially expanded. In particular, in study by S. Yamashita et al (3) an independent predictor of oncological prognosis for patients with $\mathrm{mCRC}$ the degree of ischemia that arose as a result of a blood supply violation in liver parenchyma during the first 30 days after the resection (liver stroke) assumed. Authors received a direct-proportional dependence between non-recurrent survival rate and stroke severity in resection area according to computed tomography (CT) data. This approach and scale of ischemia described by authors as an evidence proving that level of liver ischemia after the surgery can be a significant predictive factor of $\mathrm{mCRC}$ patients survival rate since the time of surgical intervention. These findings confirmed by our results as well. It is known that O2- causes DNA oxidation leading to formation a number of oxidative bases and nucleotides in DNA. Such lesions become a cause of mutations and carcinogenesis initiation in healthy people or in malignant neoplasms progression, including those with CRC. 8-hydroxy-deoxyguanosine is the most frequently reported form of oxidative bases in DNA or in a nuclear pool. It has dangerous effects because of capacity to form pairs with adenine and/or cytosine in DNA molecule (32).

8-oxoG is able to accumulate in both nuclear and mitochondrial DNA. That is why the latter considered a highly informative marker of malignant neoplasms formation (32). Among the guanine residues the nucleic acids variation is possible, hence the modification of 8-oxoguanine to deoxyguanosine ( $\mathrm{dG}$ ) may have place; inC-8 sitedG molecule is most effectively oxidised by ascorbic acid generating 8-oxo-2'-deoxyguanosine (8-OHdGu).

The main cause of mCRC in intestinal mucosa is considered to be agene mutation that controls cell cycle (proliferation, differentiation, adhesion and apoptosis) $(7,11)$. Oxidative damage of nuclear and mitochondrial DNA, hypermethylation of gene promoters is a major event at all stages of carcinogenesis. Prolonged exposure of intestinal mucosa to O2-. initiates chronic inflammation and dysplasia. Disorders caused by $\mathrm{O2}$. include oxidative-induced mutations in genome, its functional instability and consequently cell proliferation dysregulation (12-14). The integral quantitative analysis of urine $8-\mathrm{OHdGu}$ providesan opportunity to noninvasive evaluation of degree of DNA oxidation and redox condition of tissue after surgery.

The aim of our study is to evaluate the clinical significance of 8-hydroxy-deoxyguanosine marker, to assess the oncological effects of heat ischemia of liver parenchyma on disease prognosis in patients with mCRC.

\section{MATERIAL AND METHODS}

The study involved 69 CRC patients with metachronous metastatic liver disease, ( $\mathrm{pT}$ 1-4No-2Mo colon

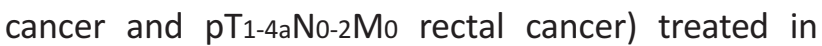
National Cancer Institute from March 2015 till Jun 2018. 36 men and 33 women included in the study. Average age of patients was $61.4 \pm 2.3$ years. 28 patients were diagnosed rectal cancer, while 41 - colon cancer. Based on degree of tumor differentiation patients distributed as follows: G1-2-tumors found in 23 patients, G3-4 tumors - in 46 patients (table 1).

In each clinical case, multidisciplinary approach used 
Table 1 - Group characteristics for participating patients

\begin{tabular}{|c|c|}
\hline Characteristics & Value \\
\hline Age & $61.4 \pm 2.3$ \\
\hline Body mass index & $26.5 \pm 5.3$ \\
\hline Sex (male/female) & $36 / 33$ \\
\hline Metastatic liver injury (synchronous/metachronous) & $14 / 55$ \\
\hline Primarytumorlocation (rectum/colon) & $25 / 44$ \\
\hline Metastatic injury of other sites at the moment of liver resection (lungs/ abdomen cavity) & $4 / 5$ \\
\hline Number of resected metastases & $3.41 \pm 1.3(4-7)$ \\
\hline Volume of metastatic tissue in liver $\left(\mathrm{cm}^{3}\right)$ & $9.2 \pm 7.3(1.0-43.2)$ \\
\hline Type of liver resection (major/minor) & $45 / 24$ \\
\hline Noeadjuvant chemotherapy (yes/no) & $17 / 52$ \\
\hline \multicolumn{2}{|l|}{ Patient condition (ASA scale): } \\
\hline$|-| \mid$ & 47 \\
\hline III & 22 \\
\hline Warm ischemia duration during the Pringle manuever (min.) & $19.7 \pm 20.5$ \\
\hline Duration of liver parenchyma transection (min.) & $228.9 \pm 118.2$ \\
\hline Pringle manoeuvre applied (yes/no) & $51 / 18$ \\
\hline
\end{tabular}

where surgeons, oncologists, chemotherapists and radiologists took part. In all cases, the diagnosis of metastatic liver damage confirmed using cytology/ histology techniques and fine-focal biopsy of the pathological liver sites. Routine computer tomography (CT) with intravenous contrast of thoracic, abdominal and pelvic cavity applied; and in complicated cases (suspicion of canceromatosis or bilobar lesions) the examination supplemented by magnetic resonance imaging (MRI) with intravenous contrast. Positronemission tomography (PET) used only in case of metastatic involvement of other organs/sites.

Surgical technique included the implementation of radical resection with the maximum possible preservation of parenchyma and ensuring adequate retreat from the tumor edge $(4-10 \mathrm{~mm})$. Each operation accompanied by intraoperative ultrasound examination in order to mark sites in relation to major hepatic veins and Glissonian pedicles and also to detect small metastases. Major liver resections reffered to removal of 3 or more liver segments (class Couinaud). The technique of ischemia assumed the use of classic and selective Pringle maneuver [(MP) 20 min. - ischemia, and 5 min reperfusion] (8). Parenchyma transsection performed using the "crash clamp" method. Resected parenchyma hemostasis performed by prolene 4.0, 5.0 flashing, bipolar forceps, clipping of LT200, LT300.

Patients received adjuvant chemotherapy (ctx) according to international standards FOLFOX-6/ FOLFIRI/XELOX (4-6 courses). Patients treated with ctX and with signs of with disease progression did not undergo liver resection. Functional liver capacity assessed using Child-Turcotte-Pugh score and MELD score. The manifestations of chemotherapy toxicity documented according to STCAE 5.0 criteria. The degree of acute liver failure (ALF) in postoperative period determined by International Study Group of Liver Surgery (ISGLS) classification.

Urine sampling done 24-hours before the surgery and on day 3 since it performed. Then $20 \mathrm{ml}$ of 24-hour volume test urine filtered through a solid-phase extraction column. Measurement of $8-\mathrm{OHdGu}$ level in eluate carried out using spectrophotometric method (9). The energy system and hepatocyte detoxification system state, 02-. generation speed in tumor tissue, hepatocyte mitochondria and tissue-associated neutrophils determined using method of electron paramagnetic resonance (EPR) and technology of spin traps (SpinTraps) at room temperature. Measurements carried out on a computerized EPR spectrometer RE-1307. EPR spectra recorded at liquid nitrogen temperature (-196 ${ }^{\circ} \mathrm{C}$ ) in a paramagnetically pure quartz dewar on a computerized spectrometer PE-1307 with resonator Ho11. Following parameters used: power of microwave source level - $40 \mathrm{~mW}$, modulation frequency- $100 \mathrm{kHz}$, amplitude - 10 Gaussian, the receiver's constant time $\tau$ $=0.3 \mathrm{sec}$. As a standard of intensity a specially oriented sample of a single crystal $\mathrm{Al}_{2} \mathrm{O}_{3}$ with specific concentration of $\mathrm{Cr}^{3+}$ ions used. Method of double integration evaluated the concentration of molecules by comparing 
the signals intensity in EPR spectra tostandart intensity. Error of spectrum integration method and spread of spectrum reproduction of one sample was within $3 \%$.

Statistical analysis of the results performed using IBM SPSS Statistics (Version 20.0, Armonk, NY, USA). T-test used to evaluate the difference of urine $8-\mathrm{OHdGu}$ between healthy individuals and $\mathrm{MCRC}$ patients. Concentration on urine $8-\mathrm{OHdG}$ at different disease stages compared using one-way ANOVA test. Logistic regression model designed to determine the relation between the urine 8-OHdGu concentrations in patients with $\mathrm{CRC}$ and other factors i.e. body mass index (BMI), presence of ischemic liver tissue, presence of distant metastases, volume of metastatic tissue in liver, stage of process, age, sex, degree of tumor differentiation. Statistical significance assumed when $p<0.05$.

\section{RESULTS AND DISCUSSION}

We have analyzed urine 8-oxodGu levels in mCRC patients before and after the liver metachronous metastases removal (fig. 1). Our data show that metastatic tissue removal leads to normalization of oxidative DNA damage. Thus, the average level of marker in healthy individuals urine is $0.244 \pm 0.063$
$\mathrm{nM} / \mathrm{kg} \cdot$ day, whereas on day 3 after the R0-resection of liver due to its metastatic lesion - $3.42 \pm 0.18 \mathrm{nM} / \mathrm{kg}$. day and $2.12 \pm 0.08 \mathrm{nM} / \mathrm{kg} \cdot$ day $(\mathrm{p}<0.05)$.

Figure 2 shows the results of urine $8-\mathrm{OHdGu}$ levels in $\mathrm{MCRC}$ on day 3 fater the surgery with different warm liver ischemia duration during the MP. Mean value of urine $8-\mathrm{OHdGu}$ in healthy individuals - $0.244 \pm 0.063$ $\mathrm{nM} / \mathrm{kg} \cdot$ day. In patients with $\mathrm{mCRC}$ on 3 day after the liver resection due to its metastatic lesion with a total duration of heat ischemia $<30 \mathrm{~min}$ and $>30 \mathrm{~min}-2,108$ $\pm 0.13 \mathrm{nM} / \mathrm{kg} \cdot$ day and $2.9883 \pm 0.159 \mathrm{nM} / \mathrm{kg} \cdot$ day $(p<0.0001)$, respectively. Obviously, urine level of $8-\mathrm{OHdGu}$ is significantly increased in patients with $\mathrm{mCRC}$ and depends on warm ischemia duration caused by MP (fig. 2).

We have studied a number of markers and factors that could negatively affect the level of oxidative DNA damage and subsequently the oncologic prognosis in our cohort of mCRC patients (table 2). It was shown that statistically significant effect registered with volume of metastatic tissue in liver $(p=0.037)$, duration of warm ischemia during the liver parenchyma transsection $(p=0.001)$ and duration of surgery $(p=0.006)$.

Statistical analysis of studied factor dependence on oxidative DNA damage (8-oxodGu) level show that

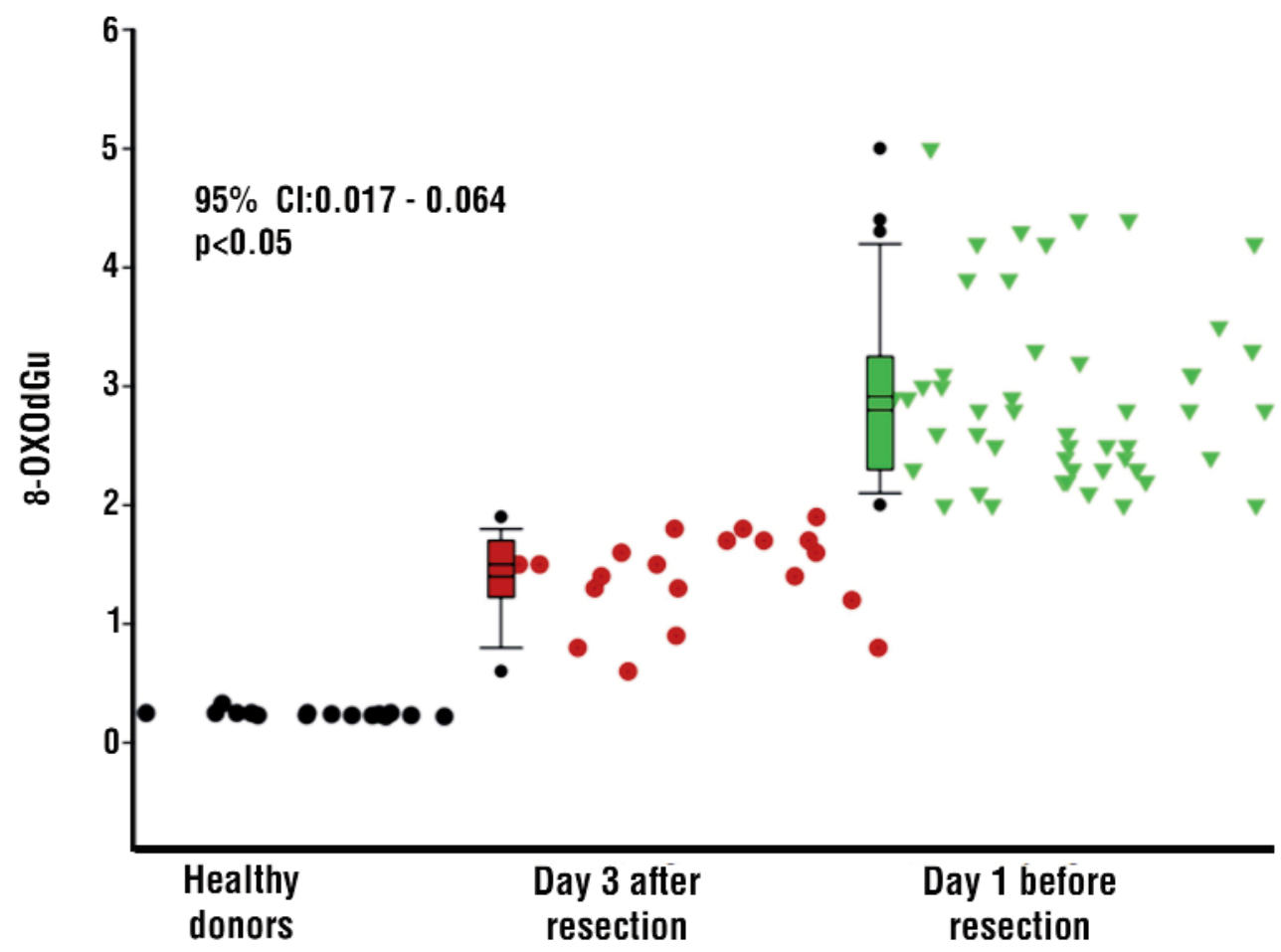

Figure 1 - Urine 8-oxodGu levels ( $\mathrm{nM} / \mathrm{kg}$ · day) in patients: normal - healthy individuals $(\mathrm{n}=17)$; " day 1 before resection $(n=30) /$ day 3 after the liver resection" $(n=30)$ in mCRC patients 


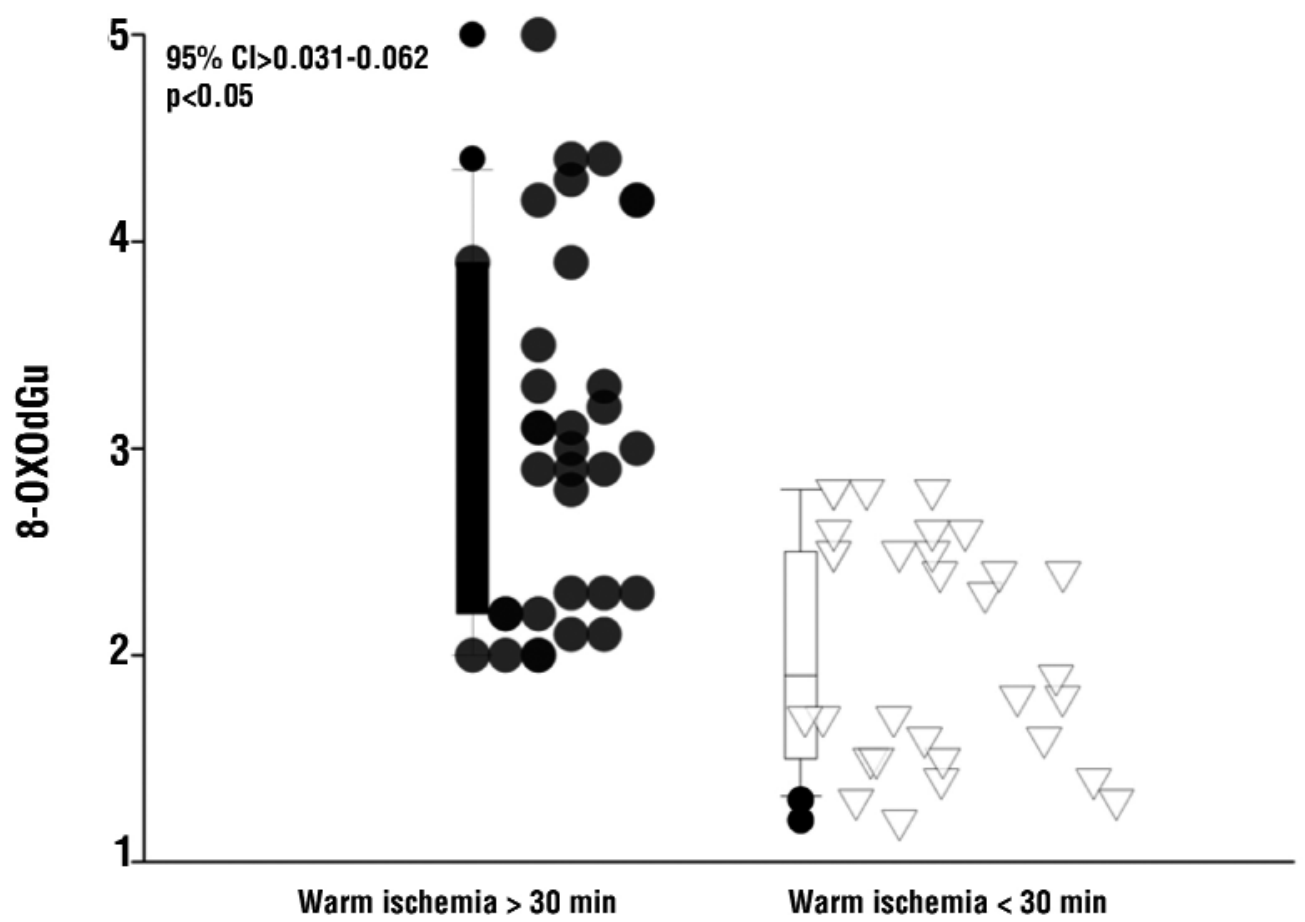

Figure 2 - Urine 8-0HdGu levels in mCRC patients: ischemia $<30 \mathrm{~min}$ - mCRC patients (on day 3 after R0-resection of liver) whom PM applied with a total duration of heat ischemia less than $\mathbf{3 0}$ minutes; ischemia $>\mathbf{3 0}$ min - mCRC patients (on day $\mathbf{3}$ after R0-resection of liver) whom PM applied with a total duration of heat ischemia $>30 \mathrm{~min}$.

duration of liver parenchyma transection, warm ischemia during and volume of metastatic tissue in liver are independent factors that adversely affect the level of studied marker (fig. 3). In particular, the volume of metastatic tissue $\left(\mathrm{V}_{\mathrm{mts}}\right)$ significantly and proportionally increases the level of urine 8-oxodGu in surgery-treated patients ( $\mathrm{R} 2=0.54 .95 \% \mathrm{Cl}: 0.037-0.0991$ at $\mathrm{p}<0.0001$ ) (fig. 3a). Surgery time (tresection) and duration of heat

Table 2 - Results of linear linear regression of analyzed factors in mCRC patients

\begin{tabular}{|c|c|c|c|c|c|c|}
\hline \multirow[t]{2}{*}{ Model } & \multicolumn{2}{|c|}{$\begin{array}{l}\text { Non-standard } \\
\text { coefficients }\end{array}$} & $\begin{array}{l}\text { Standard } \\
\text { coefficients }\end{array}$ & $T$ & \multirow[t]{2}{*}{ Significance } & \multirow[t]{2}{*}{$\begin{array}{c}95.0 \% \text { Conf } \\
\text { Interval } \\
\text { Lower limit }\end{array}$} \\
\hline & & & Standard error & Beta & & \\
\hline Constant & 1,235 & 0,172 & & 7,167 & 0,000 & 0,891 \\
\hline Vmts & 0,064 & 0,013 & 0,486 & 4,738 & 0,000 & 0,037 \\
\hline tresection & 0,003 & 0,001 & 0,345 & 3,369 & 0,001 & 0,001 \\
\hline Age & 0,023 & $-0,034$ & 0,071 & 0,042 & 0,930 & 1,076 \\
\hline $\mathrm{T}$ & 0,443 & 0,300 & 0,150 & 0,089 & 0,659 & 1,517 \\
\hline$N$ & 0,638 & 0,414 & 0,111 & 0,066 & 0,461 & 2,170 \\
\hline G & $-0,071$ & $-0,373$ & $-0,323$ & $-0,201$ & 0,834 & 1,199 \\
\hline Pringle & 0,786 & 0,453 & 0,308 & 0,190 & 0,721 & 1,387 \\
\hline BMI & 0,016 & $-0,020$ & $-0,121$ & $-0,072$ & 0,900 & 1,111 \\
\hline tIschemia & 0,017 & 0,005 & 0,352 & 3,277 & 0,002 & 0,006 \\
\hline
\end{tabular}

$\mathrm{BMI}$ - body mass index; Pringle - Pringle maneuver (yes/no); G - degree of tumor differentiation; $\mathrm{N}$ - status of regional lymph nodes; $\mathrm{T}$ - status of primary tumor, tichemia - duration of heat ischemia during the transection of liver parenchyma, tresection - duration of liver surgery, min, Vmts - volume of metastatic tissue based on CT-volumetry results, $\mathrm{cm}^{3}$. 
ischemia during the surgical manipulations (tischemia) surgery-treated patients ( $\mathrm{R} 2=0.54,95 \% \mathrm{Cl}$ : 0.001 significantly increased level of urine 8 -oxodGu in 0.004 at $p<0.001)$, (fig. $3 b, 3 c$ ).



$R^{2}=0.54$

$95 \%$ Cl:0.037 - 0.091

$\mathrm{p}<0.000$

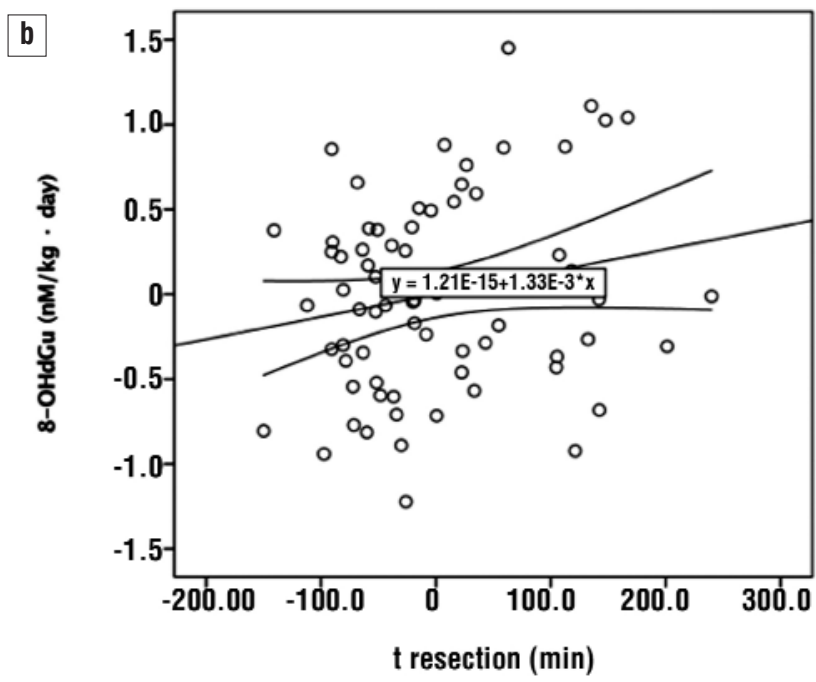

$R^{2}=0.54$

95\% Cl: $0.001-0.004$

$\mathrm{p}<0.001$

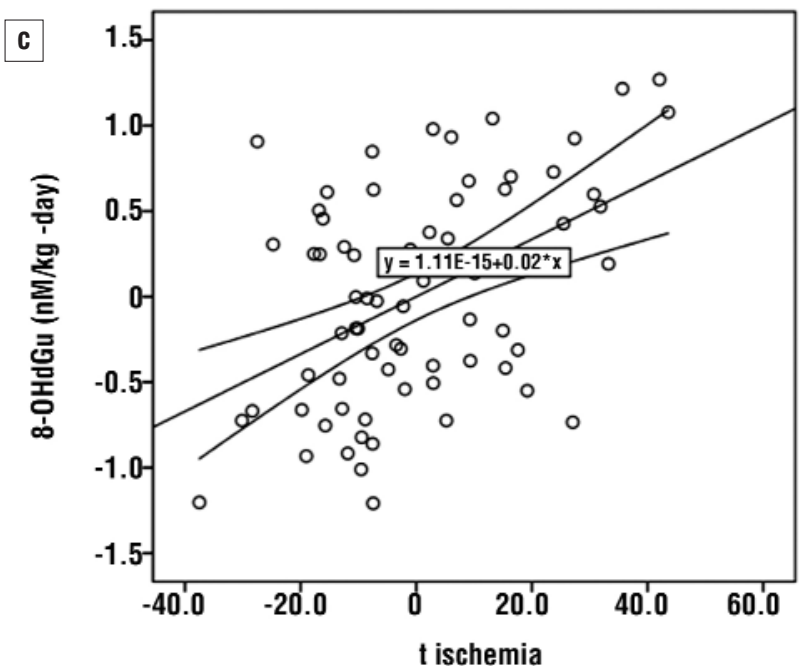

Figure 3 - Graphical representation of linear regression model showing: a - effect of volume of metastatic liver tissue (Vmts); $\mathbf{b}$ - duration of liver parenchyma transection (tresection) and c - duration of heat ischemia during PM (tischaemia) on urine 8-0HdGu levels in mCRC patients.

$R^{2}=0.54$

95\% CI:0.006 - 0.011 $\mathrm{p}<0.001$ 


\section{Linear regression model equation}

We have created a linear regression equation for 8 -OHdGu marker levels $=1.253+0.483 \bullet \mathrm{V}_{\mathrm{mts}}+0.342 \bullet$ tresection $+0,352 \bullet$ tischemia.

Using EPR method under conditions of low temperature stabilization (T77K) the study of ischemic liver tissue samples and liver tissue samples dissected at a distance of $5 \mathrm{~cm}$ from the tumor node (postoperative material) done. In EPR spectra of healthy liver tissue following spectra detected: EPR signals $g=1.94$, which characterize the state of mitochondrial electron transport chain (ETC) (iron-sulfur proteins of Complex I, NADN-dehydrogenase 1a); EPR signal $g=2,00$ - level of flavo-, ubisemininone, a main electron transfer in ETC; EPR signal $g=2,03-$ level of NOFeS-protein complexes; EPR signal $g=$ 2,25 and $g=2,42$ - activity level of cytochrome P-450 (CYP) in redox cycle of hepatocyte detoxification system; ERPR signal $g=2.65$ - free iron level; EPR signal with $g=4.25$ - level of lactoferrin, transferrin functioning in oxidative metabolism in mitochondria (fig. 4). Qualitative and quantitative changes in energy and detoxification systems of ischemic liver tissue mitochondria detected.

In conditionally healthy liver tissue at a distance of 5 $\mathrm{cm}$ from the metastasis, the value of cytochrome P-450 activity detected at level $0,44 \pm 0,08$ a.u. while in healthy tissue - 1,48 $\pm 0,13$ a.u. In ischemic tissue activity of cytochrome P-450 detected at level $0.11 \pm 0.07$ a.u., which is an evidence of significant decrease of detoxification system effectiveness (fig. 4). In mitochondria of these cells reduced activity of Complex 1 (NADHubiquinone oxidoreductase) to value $0.31 \pm 0.06$ a.u. detected, while in control group - 1,51 \pm 0.10 a.u. and $0.59 \pm 0.09$ a.u. in conditionally healthy liver tissue. Decreased activity of the electron transport complexes in electron transport chain (ETC) occurs due to NO complexes with FeS proteins $(g=2.03$ ) formation, which levels are increased; and this refers to formation of triplet structure in EPR. The lattest is typical for mitochondria of malignant tumors (fig. 4, ESR spectrum 2). In liver tissue at a distance of $5 \mathrm{~cm}$ from the metastatic node, complexes NO-FeS-proteins in ETC detected at level $0.25 \pm 0.07$ a.u. These changes in hepatocytes ETC functioning in ischemic liver tissue cause an increase in mitochondrial 02-. generation rate up to $0.81 \pm 0.09$ $\mathrm{nM} / \mathrm{g}$ tissue $\cdot \min$. Mitochondria of conditionally healthy liver tissue generate $02-$. at level $0.73 \pm 0.07$ $\mathrm{nM} / \mathrm{g}$ tissue $\cdot \mathrm{min}$. Ischemic liver cells generate $\mathrm{O2}$-.at level $1.42 \pm 0.15 \mathrm{nM} / \mathrm{g}$ tissue $\cdot$ min, conditionally healthy tissue cells produce O2-. at level $0.96 \pm 0.12$

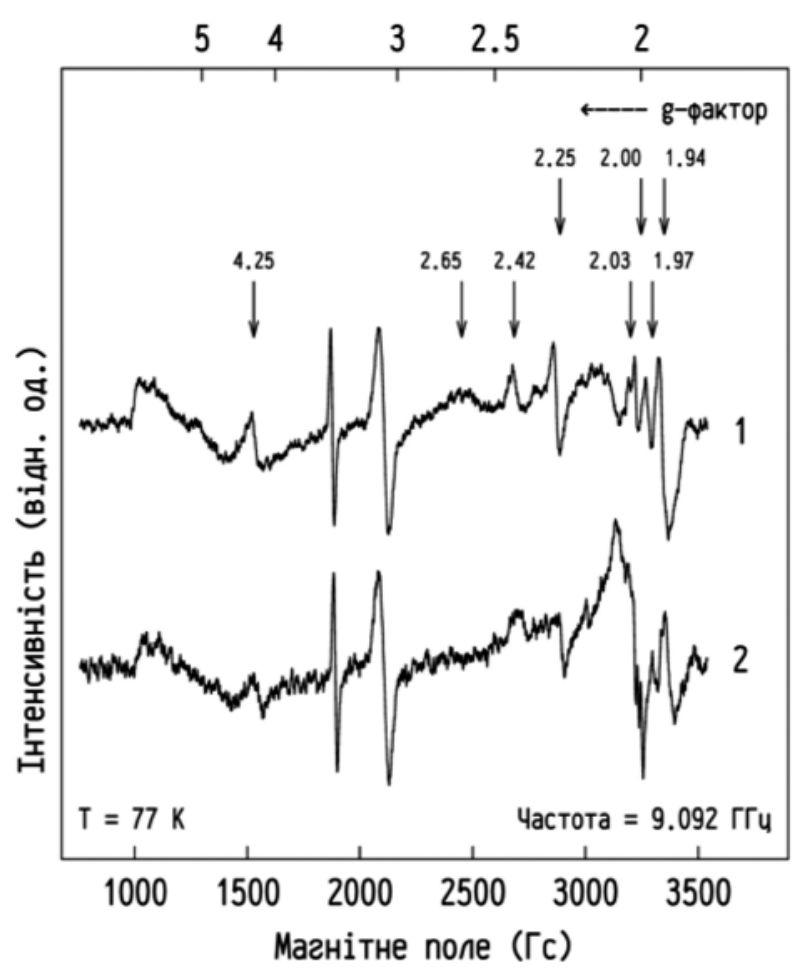

Figure 4 - ESR spectra of tissue: 1 - conditionally healthy liver. 2 - ischemic liver.

$\mathrm{nM} / \mathrm{g}$ tissue $\cdot \min ($ fig. 4 ). Our results suggest the contribution of other producers of oxygen radicals, in particular NOX neutrophils, which infiltrate affected tissues. In liver tissue, under ischemia, a decrease of molybdenum-containing enzymes activity - xanthine and aldehyde oxidase $(g=1.97)$ found, which leads to toxic products of purines and aldehydes destruction accumulation.

Detected changes in ischemic tissue mitochondria functioning cause a violation of energy metabolism (decrease ATP levels), enhanced anaerobic glucose metabolism, lactate accumulation. An ATP synthesis reduction leads to acute cellular swelling (edema) - one of the earliest manifestations of ischemic injury, decreased intracellular levels of $\mathrm{Na}+$ and increased intracellular $\mathrm{Ca}^{2+}$ concentration, which facilitates the activation of proapoptic pathways. Restoration the oxygen tissues supply as a result of reperfusion causes unregulated O2-. generation in hepatocyte mitochondria and NOX of leukocytes and platelets, inducing the opening of mitochondrial pores and cell apoptosis $(15-17,21)$.

Liver ischemia is a risk factor in case of its transplantation and resection (18), and the growth of O2-. levels in hepatocyte and tissue mitochondria is a hallmark not only of ischemic tissue, but also of many diseases (neurodegenerative, cardiovascular, chronic inflammation), - 
those associated with enhanced O2-. generation (19). However, O2-. is known to be a key factor in cell apoptosis induction, in particular in hepatocytes, which in turn plays an important role in ALF development after resection (20-21). In addition, persistent oxidative stress contributes to pathological progression of liver fibrosis and increases the risk of surgery-treated organ functional failure.

Our results and the results of other authors suggest that human mCRC tumors, tumor cell lines have significantly higher levels of 8-OHdGu than normal tissues or normal cell lines $(10,22-23)$. The key point is that the growth and development of malignant neoplasms is accompanied with steadely increase of 02-. generation level produced as a result of mitochondrial ETC dysfunction (24-26). Oxidative modification of DNA can lead to cytotoxic effects that are fundamental in pathogenesis of many diseases, including neurodegenerative, cardiovascular, chronic inflammatory diseases and cancer (27-30). 8-OHdGu formation leads to transcription violations due awitch $\mathrm{G}: \mathrm{C}$ to $\mathrm{T}: \mathrm{A}$. Moreover, formation of 8-OHdGu may cause decreased microsatellites formation and accelerate the telomer reduction $(10,31)$. Our results indicate a significant increase of urine 8-OHdGu levels in $\mathrm{MCRC}$ patients. This can be an informative biomarker for evaluation of metastatic organ damage in $\mathrm{mCRC}$ patients.

\section{CONCLUSIONS}

Thermal ischemia of liver during the Pringle maneuver ( $\geq 40$ minutes), long-term surgery ( $\geq 300$ minutes), and metastatic tissue volume $\left(\geq 12 \mathrm{~cm}^{3}\right)$ in liver parenchyma in patients with metastatic colorectal cancer cause damage of mitochondrial ETC (formation of NOFeS-proteins), resulting in an increase of O2-. generation rate in mitochondria and tissue, and urine $8-\mathrm{OHdGu}$ levels in these patients. R0-resection of metastases in liver in $\mathrm{MCRC}$ patients leads to decrease of urine 8-OHdGu already at day 3 after the surgery. The level of urine $8-\mathrm{OHdGu}$ in $\mathrm{mCRC}$ patients correlates with the volume of resection, duration of ischemia, volume of post-ischemic liver tissue, volume of tumor tissue in liver and the rate of O2-. generation in tumor tissue and degree of tumor differentiation. Urine 8-OHdGu levels are significantly higher in patients with long-term metastases as compared to those in patients who did not have metastases. Levels of urine 8-OHdGu, level of intraoperative and postoperative ischemia of liver parenchyma are new factors of oncological prognosis in patients with rectal forms of metastatic colorectal cancer that affect the liver.

\section{Conflict of interest}

All author declare that they have no conflict of interest.

\section{REFERENCES}

1. Strandberg Holka P, Eriksson S, Eberhard J, Bergenfeldt M, Lindell G, Sturesson C. Significance of poor performance status after resection of colorectal liver metastases. World J Surg Oncol. 2018;16(1): 3.

2. Tsai HL, Chen YT, Yeh YS, Huang CW, Ma CJ, Wang JY. Apical lymph nodes in the distant metastases and prognosis of patients with stage III colorectal cancer with adequate lymph node retrieval following FOLFOX adjuvant chemotherapy. Pathol Oncol Res. 2018 Jan 3. doi: 10.1007/s12253-017-0381-5. [Epub ahead of print]

3. Yamashita S, Venkatesan AM, Mizuno T, Aloia TA, Chun YS, Lee JE, et al. Remnant liver ischemia as a prognostic factor for cancer specific survival after resection of colorectal liver metastases. JAMA Surg. 2017 Oct 18;152(10):e172986.

4. Govaert KM, Emmink BL, Nijkamp MW, Cheung ZJ, Steller EJ, Fatrai $\mathrm{S}$, et al. Hypoxia after liver surgery imposes an aggressive cancer stem cell phenotype on residual tumor cells. Ann Surg. 2014;259(4): 750-9.

5. Miyashita T, Nakanuma S, Ahmed AK, Makino I, Hayashi H, Oyama K, et al. Ischemia reperfusion-facilitated sinusoidal endothelial cell injury in liver transplantation and the resulting impact of extravasated platelet aggregation. Eur Surg. 2016;48:92-98. Epub 2015 Oct 14.

6. Tohme S, Kameneva MV, Yazdani HO, Sud V, Goswami J, Loughran $P$, et al. Drag reducing polymers decrease hepatic injury and metastases after liver ischemia-reperfusion. Oncotarget. 2017; 8(35): 59854-59866.

7. Ortega AL, Mena S, Estrela JM. Oxidative and nitrosative stress in the metastatic microenvironment. Cancers (Basel). 2010;2(2): 274-304.

8. Chouillard EK, Gumbs AA, Cherqui D. Vascular clamping in liver surgery: physiology, indications and techniques. Ann Surg Innov Res. 2010;4:2.

9. Burlaka AP, Sidorik EP. Radical forms of oxygen and nitrogen oxide in the tumor process. Kyiv: Naukovadumka; 2006, p . 227.

10. Burlaka AP, Ganusevich II, Golotiuk VV, Vovk AV, Lukin SM. Superoxide- and NO-dependent mechanisms of antitumor and antimetastatic effect of L-arginine hydrochloride and coenzyme Q10. Exp Oncol. 2016;38(1):31-5.

11. Burlaka AP, Sidorik EP. Redox-dependent signal molecules in mechanisms of tumor process. Kyiv: Naukovadumka; 2014, p. 255.

12. Saha SK, Lee SB, Won J, Choi HY, Kim K, Yang GM, et al. Correlation between Oxidative Stress, Nutrition, and Cancer Initiation. Int J Mol Sci. 2017;18(7). pii: E1544.

13. Ribeiro ML, Priolli DG, Miranda DD, Arçari DP, Pedrazzoli $\mathrm{J} J \mathrm{Jr}$, Martinez CA. Analysis of oxidative DNA damage in patients with colorectal cancer. Clin Colorectal Cancer. 2008;7(4):267-72.

14. Szymczak I, Sliwinska A, Drzewoski J. DNA damage and efficacy of DNA repair in patients with type 2 diabetes and coexisting colorectal cancer. Pol Arch Med Wewn. 2014;124(7-8):352-8.

15. Hu H, Nan J, Sun Y, Zhu D, Xiao C, Wang Y, et al. Electron leak from NDUFA13 within mitochondrial complex I attenuates ischemiareperfusion injury via dimerized STAT3. Proc Natl Acad Sci USA. 2017;114(45):11908-11913.

16. Sun K, Liu ZS, Sun Q. Role of mitochondria in cell apoptosis during hepatic ischemia-reperfusion injury and protective effect of ischemic postconditioning. World J Gastroenterol. 2004;10(13):1934-8.

17. Vardanian AJ, Busuttil RW, Kupiec-Weglinski JW. Molecular mediators of liver ischemia and reperfusion injury: a brief review. Mol Med. 2008; 14(5-6):337-45.

18. Bystrom P, Foley N, Toledo-Pereyra L, Quesnelle K. Ischemic preconditioning modulates ROS to confer protection in liver ischemia and reperfusion. EXCLI J. 2017;16:483-496.

19. Chu MJ, Vather R, Hickey AJ, Phillips AR, Bartlett AS. Impact of 
ischaemic preconditioning on experimental steatotic livers following hepatic ischaemia-reperfusion injury: a systematic review. HPB (Oxford). 2015;17(1):1-10.

20. Reiniers MJ, van Golen RF, van Gulik TM, Heger M. Reactive oxygen and nitrogen species in steatotic hepatocytes: a molecular perspective on the pathophysiology of ischemia-reperfusion injury in the fatty liver. Antioxid Redox Signal. 2014;21(7):1119-42.

21. Burlaka AP, Vovk AV, Ganusevich II, et al. Superoxide- and NOdependent mechanisms of formation of metastatic microenvironment distant sites of metastasis in patients with colorectal cancer . Oncology 2017;19:64-70. Ukrainian

22. Scott TL, Rangaswamy S, Wicker CA, Izumi T. Repair of oxidative DNA damage and cancer: recent progress in DNA base excision repair. Antioxid Redox Signal. 2014;20(4):708-26.

23. Tudek B, Speina E. Oxidatively damaged DNA and its repair in colon carcinogenesis. Mutat Res. 2012;736(1-2):82-92.

24. Burlaka AP, Sidorik EP, Ganusevich II, Osinsky SP. Effects of radical oxygen species and NO: formation of intracellular hypoxia and activation of matrix metalloproteinases in tumor tissues. Exp Oncol. 2006;28(1):49-53.

25. Jaeschke $H$. Reactive oxygen and mechanisms of inflammatory liver injury: Present concepts. J Gastroenterol Hepatol. 2011;26 Suppl 1:173-9.

26. Peiris-Pagès $M$, Martinez-Outschoorn UE, Sotgia $F$, Lisanti MP.
Metastasis and Oxidative Stress: Are Antioxidants a Metabolic Driver of Progression? Cell Metab. 2015;22(6):956-8.

27. Stagos D, Goutzourelas N, Ntontou AM, Kafantaris I, Deli CK, Poulios A, et al. Assessment of eccentric exercise-induced oxidative stress using oxidation-reduction potential markers. Oxid Med Cell Longev. 2015;2015:204615.

28. Suehiro K, Tanaka K, Matsuura T, Funao T, Yamada T, Mori T, et al. Preoperative hydroperoxide concentrations are associated with a risk of postoperative complications after cardiac surgery. Anaesth Intensive Care. 2014;42(4):487-94.

29. Schwarz C, Fitschek F, Bar-Or D, Klaus DA, Tudor B, Fleischmann E, et al. Inflammatory response and oxidative stress during liver resection. PLoS One. 2017;12(10):e0185685.

30. Sliwinska A, Kwiatkowski D, Czarny P, Toma M, Wigner P, Drzewoski J, et al. The levels of 7,8-dihydrodeoxyguanosine (8-oxoG) and 8-oxoguanine DNA glycosylase 1 (OGG1) - A potential diagnostic biomarkers of Alzheimer's disease. J Neurol Sci. 2016;368:155-9.

31. Nakabeppu Y. Cellular levels of 8-oxoguanine in either DNA or the nucleotide pool play pivotal roles in carcinogenesis and survival of cancer cells. Int J Mol Sci. 2014;15(7):12543-57.

32. Nakabeppu Y, Sakumi K, Sakamoto K, Tsuchimoto D, Tsuzuki T, Nakatsu $Y$. Mutagenesis and carcinogenesis caused by the oxidation of nucleic acids. Biol Chem. 2006;387(4):373-9. 